\title{
Crystal growth and characterisation of organic-inorganic lead-free 2D double perovskite for application in radiation sensing
}

\author{
V. Murgulov', C. Schweinle ${ }^{2}$, M. Daub ${ }^{1,2}$, H. Hillebrecht ${ }^{1,2}$, M. Fiederle ${ }^{1}$ \\ ${ }^{I}$ Freiburg Materials Research Center FMF, Albert-Ludwigs-Universität Freiburg, Germany \\ ${ }^{2}$ Institute of Inorganic and Analytical Chemistry, Faculty of Chemistry and Pharmacy, Albert-Ludwigs-Universität Freiburg, \\ Germany \\ valeria.murgulov@fmf.uni-freiburg.de
}

Single crystals of lead-free organic-inorganic $2 \mathrm{D}(\mathrm{BA})_{2} \mathrm{CsAgBiBr}_{7}$ with double perovskite structure (monoclinic, $P 2_{1} / m$ ) exhibit a significant potential for X-ray sensing [1]. This stems from their heavy elements constituting the perovskite octahedral network that is in an alternating arrangement with the barrier layer of organic $\mathrm{BA}^{+}$cations, consequently producing desirable electrical properties. In this study, several yellow-coloured single crystals of $(\mathrm{BA})_{2} \mathrm{CsAgBiBr}$ were grown from a low-temperature solution [2]. All crystals are characterised by growth/dissolution features and defects (Figure 1). The phase purity and crystallinity of all samples have been verified from the powder XRD data. High ordering of $\mathrm{Ag}^{+}$and $\mathrm{Bi}^{3+}$ octahedra cations is apparent from the XRD patterns for single crystals, which depict peaks arising from the $\{001\}$ plane.

Results from electrical characterisation of the single crystals of $(\mathrm{BA})_{2} \mathrm{CsAgBiBr}$ reveal high resistivity $\left(10^{11} \Omega \mathrm{cm}\right)$ and low density of trap states $\left(10^{11}-10^{12} \mathrm{~cm}^{-3}\right)$, which are comparable to those published in literature [1]. This implies that the samples synthesised in this study also satisfy requirements for radiation sensors.

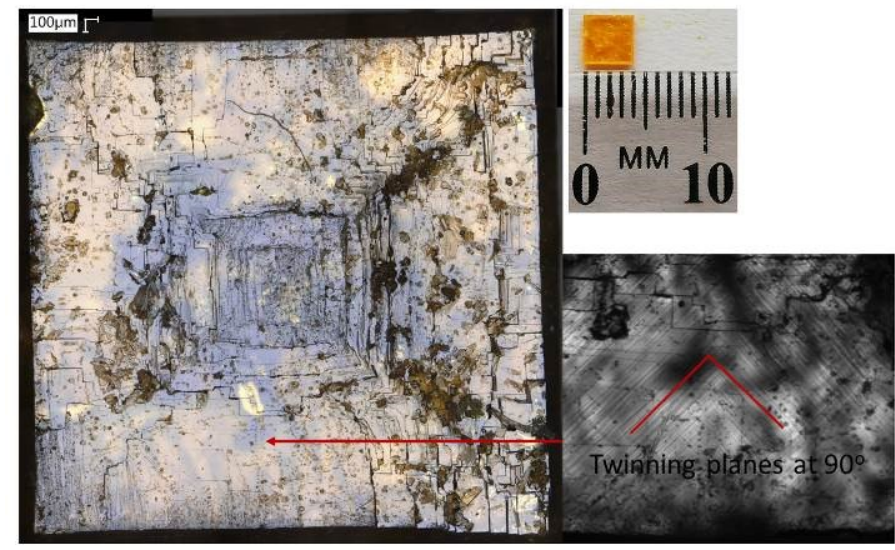

Figure 1. The top crystal surface of the sample $(\mathrm{BA})_{2} \mathrm{CsAgBiBr}_{7}$ Exp1 (top right corner, 4 x 4 x $0.75 \mathrm{~mm}^{3}$ ) is characterised by irregular growth /dissolution features (image on the left made in reflected light, $100 \mu \mathrm{m}$ scale bar) and defects such as twinning planes at $90^{\circ}$ (image on the right made in transmitted light).

[1] Xu, Z., Liu, X., Li, Y., Liu, X., Yang, T., Ji, C., Han, S., Xu, Y., Luo, J., \& Sun, Z. (2019). Angew. Chem. Int. Ed. 58, 15757.

[2] Connor, B. A., Leppert, L., Smith, M. D., Neaton, J.B., \& Karunadasa, H. I. (2018). J. Am. Chem. Soc. $140,5235$.

Keywords: 2D layered single crystals, double perovskite, crystal growth, crystal structure, electrical properties 